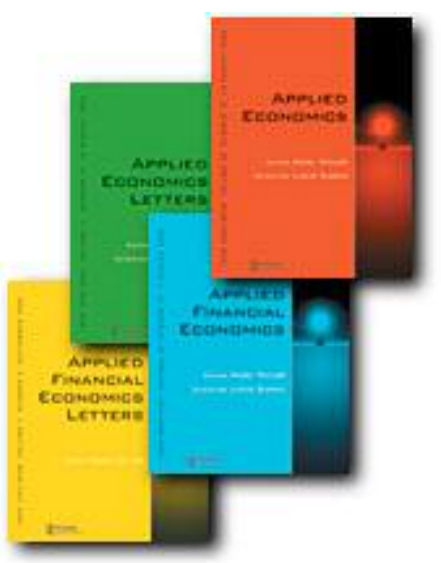

The price effects of joining the Euro: Modelling the Greek experience using non-linear price-adjustment models

\begin{tabular}{|c|c|}
\hline Journal: & Applied Economics \\
\hline Manuscript ID: & APE-04-0170 \\
\hline Journal Selection: & Applied Economics \\
\hline $\begin{array}{r}\text { Date Submitted by the } \\
\text { Author: }\end{array}$ & 09-Nov-2004 \\
\hline JEL Code: & $\begin{array}{l}\text { C51 - Model Construction and Estimation < C5 - Econometric } \\
\text { Modeling < C - Mathematical and Quantitative Methods, C52 - } \\
\text { Model Evaluation and Testing < C5 - Econometric Modeling < C - } \\
\text { Mathematical and Quantitative Methods, E31 - Price } \\
\text { Level|Inflation|Deflation < E3 - Prices, Business Fluctuations, and } \\
\text { Cycles < E - Macroeconomics and Monetary Economics, F15 - } \\
\text { Economic Integration < F1 - Trade < F - International Economics }\end{array}$ \\
\hline Keywords: & price level, structural breaks, non linear adjustment, Euro \\
\hline
\end{tabular}




\title{
THE PRICE EFFECTS OF JOINING THE EURO: \\ Modeling the Greek experience \\ using non-linear price-adjustment models
}

\author{
by \\ Michael G. Arghyrou* \\ Economics and Finance \\ Brunel Business School \\ Brunel University
}

\begin{abstract}
We test the widely-held hypothesis that accession to the EMU has caused a structural increase in Greek consumer prices. We find no econometric evidence of such an effect. We also find strong evidence of (a) multiple structural breaks in the process driving Greek equilibrium consumer prices and (b) non-linear price adjustment. Our findings explain the post-EMU accession acceleration in Greek prices as normal, equilibrium-restoring behaviour. They also have important policy implications for the countries planning to join the Euro in the foreseeable future.
\end{abstract}

Keywords: price level; structural breaks; non-linear adjustment; Euro

JEL Classification: C51; C52; E31; F15

*Address for correspondence:

Michael G. Arghyrou, Economics and Finance, Brunel Business School, Brunel University, Uxbridge, Middlesex, UB8 3PH, United Kingdom. Tel. No: ++441895203179; Fax No: ++441695203384 ; e-mail: Michael.Arghyrou@brunel.ac.uk 


\section{INTRODUCTION}

The accession of Greece to the European Economic and Monetary Union (EMU) in January 2001 was followed by a noticeable increase in the level of Greek consumer prices. This has given rise to a widely-held held hypothesis according to which the Euro has caused a structural shift in the Greek price level.

Such a hypothesis can theoretically be supported by the price-transparency properties of the single currency. These are typically regarded to be among the benefits of the latter, as they are expected to promote price competition in the traded sector, reduce price differentials associated with exchange rate variability; and limit the ability of firms to follow pricing-to-market policies. ${ }^{1}$ However, in countries like Greece, with large public and services sectors, the aggregate price level is significantly determined by the non-traded component. ${ }^{2}$ A widely accepted stylised fact is that in such countries, where productivity and per capita income are lower than in more developed ones, prices in the non-traded sector, as well as the aggregate price level, are relatively low when expressed in terms of a common currency. $^{3}$ In addition, and according to the Balassa (1964)-Samuelson (1964) hypothesis, when less developed countries achieve productivity gains, their aggregate price level tends to increase. ${ }^{4}$

In the case of Greece, the above imply that by making comparisons of nontraded prices more transparent (contributing to upward rather than downward price equalisation), and by providing domestic firms with an extra motivation to increase their productivity due to the loss of the competitiveness-inducing option of currency depreciation (giving rise to a Balassa-Samuelson type of effect), accession to the Euro may have caused a structural increase in Greek consumer prices. In this paper, we test this hypothesis and soundly reject it. We then look for alternative 
explanations for the post-EMU accession increase in Greek consumer prices. To that end, we model Greek equilibrium consumer prices and the process of short-run price adjustment following the methodology used by Arghyrou, Martin and Milas (2004).

The theoretical literature on non-linear (state-dependent) price adjustment (see e.g. Deveraux and Siu (2004) and the references therein) suggests that menu costs and other market imperfections result in firms adjusting prices only when they differ from their equilibrium level enough to render adjustment profitable. Not accounting for such non-linearities, when they exist, may lead to biased econometric inference. Similar biases arise if the relationship determining equilibrium prices is treated as a structurally stable process when in reality it has been subject to structural breaks (see Madalla and Kim, 1998).

Our econometric analysis accounts for both sources of bias mentioned above. We test a joint hypothesis, according to which the process driving long-run equilibrium prices is structurally stable and, at the same time, characterised by a linear adjustment process. We reject both constituents of this joint hypothesis as we find evidence of both multiple structural breaks and non-linear price adjustment. The identified structural breaks are found not to be related to the accession of Greece to the EMU. With regard to non-linearities, we find Greek consumer prices to converge always to their steady-state; however convergence is found to be much faster when prices are away rather than close to their equilibrium.

These findings help us to explain the post-EMU accession increase in Greek consumer prices on the following grounds. First, we argue that consumer prices increased at the early stages of EMU participation because they had taken values increasingly below their equilibrium level prior to EMU accession. As a result, 
restoring equilibrium was bound to involve accelerated price increases. Second, we claim that the post-accession increase in prices was sharp because the pre-accession under-pricing episode was big enough to set in motion the high speed of price adjustment identified by our non-linear price adjustment analysis. We conclude that the post-EMU accession behaviour of Greek prices is not surprising: It represents normal equilibrium-restoring behaviour. These findings have important policy implications for the countries that have recently joined the EU and plan to join the single currency in the foreseeable future.

The remainder of this paper is structured as follows: Section 2 discusses our methodology and presents our empirical results. Section 3 discusses our findings. Finally, section 4 summarises and offers some concluding remarks.

\section{METHODOLOGY AND EMPIRICAL RESULTS}

\subsection{Benchmark models of equilibrium prices and price adjustment}

Following the analysis in Arghyrou, Martin and Milas (2004), our first step is to estimate the benchmark models for Greek equilibrium prices and price adjustment respectively described by equations (1) and (2) below: ${ }^{5}$

$p_{t}=\alpha+\beta_{1} u l c_{t}+\beta_{2} p w_{t}+u_{t}$

$\Delta p_{t}=\sum_{i=1}^{k} \beta_{i} \Delta p_{t-i}+\sum_{i=0}^{m} \gamma_{i} \Delta p_{t-i}+\delta\left(p-p^{*}\right)_{t-1}+v_{t}$

In (1) and (2), $p$ denotes the actual (observed) price level; $\Delta p_{\mathrm{t}}=p_{\mathrm{t}}-p_{\mathrm{t}-1}$ the change in the actual price level (our measure of price adjustment); ulc unit labour cost; $p w$ the log of world prices expressed in terms of domestic currency; $p^{*}$ the equilibrium price level; and $u_{\mathrm{t}}$ and $v_{t}$ white noise error terms. All variables are 
expressed in terms of logarithms. Provided that equation (1) is cointegrated, the fitted values of equation (1), denoted by $\hat{p}^{*}$, provide an estimate for the equilibrium price level $p^{*}$, with the cointegrating vector $\mathrm{CV}_{t}=p_{t}-\alpha-\beta_{1} u l c_{t}$ $\beta_{2} p w_{t}$, measured by the estimated residual term $\hat{u}_{t}$, corresponding to the disequilibrium term $\left(p-p^{*}\right)_{t}$ in (2). Substituting $\left(p-p^{*}\right)_{t}$ by $\mathrm{CV}_{t}$ modifies equation (2) as per (3) below.

$$
\Delta p_{t}=\sum_{i=1}^{k} \beta_{i} \Delta p_{t-i}+\sum_{i=0}^{m} \gamma_{i} \Delta \hat{p}^{*}{ }_{t-i}+\delta\left(p-\hat{p}^{*}\right)_{t-1}+v_{t}
$$

In (3), the parameter $\delta$ describes the speed at which the actual price level $p_{t}$ convergences to its estimated equilibrium $\hat{p}_{t} *{ }^{6}$ For our estimations we use quarterly series. Data availability limits our sample to cover the period 1971Q4 to 2003Q3. Our data source is the International Financial Statistics Databank provided by DataStream. Our measure of $p$ is the index of consumer prices (CPI). This is the headline Greek measure of prices, for which the Bank of Greece used to announce policy objectives during the 1990s and the one widely assumed to have been subject to a structural shift following Greece's accession to the EMU. World prices expressed in domestic currency $(p w)$ are calculated multiplying the index series of world consumer prices (expressed in US dollars) by the drachma/dollar exchange rate $^{7}$. Unit labour cost $(u l c)$ is approximated by the index of unit labour cost in the Greek manufacturing sector. ${ }^{8}$

Following Hendry (2001), we estimate (1) using the Engle and Granger (1987) methodology. ${ }^{9}$ The results are reported in Table 1 , col. (a). ${ }^{10}$ The estimates of $\beta_{1}$ and $\beta_{2}$ suggest dominance of the domestic component $(u l c)$ in the determination of Greek consumer prices. However, prices of imported goods $(p w)$ 
also appear to play a significant role. Not surprisingly, the reported ADF statistic suggests that (1) is cointegrated. ${ }^{11}$

We now estimate (3) using $\mathrm{CV}_{t}$, the estimated residuals of (1), as a measure of the error correction term $\left(p-\hat{p}^{*}\right)$. We follow a general-to-specific approach, initially including twelve lags for $\Delta p$ and $\Delta \hat{p}^{*}$ and gradually eliminating insignificant terms. The results are reported in Table 2, col. (a). The error correction coefficient $\delta$ is statistically significant which, according to the Granger representation theorem, confirms the existence of cointegration. However, the estimated quarterly speed of adjustment towards equilibrium is very slow (4.4 per cent), suggesting very pronounced price rigidities. ${ }^{12}$

\subsection{Tests and models of structural breaks in long-run price determination}

We now test the hypothesis that the accession of Greece to the EMU in 2001 , and/or the physical introduction of the Euro in 2002, have caused a structural increase in Greek equilibrium consumer prices. Such a test will only be credible if it takes into account any structural breaks preceding those events. To identify such breaks, we use the methodology of Gregory and Hansen (1996) to identify multiple structural breaks in cointegrating relationships endogenously. To do so, we estimate:

$p^{*}=\alpha+\beta_{1} u l c_{t}+\beta_{2} p w_{t}+d_{0} D_{t}+d_{1} \mathrm{D}_{t} u l c_{t}+d_{2} \mathrm{D}_{t} p w_{t}+u_{t}$

where

$$
\begin{aligned}
D_{t} & =1 & \text { if } & \mathrm{t} \in(1, \ldots, T) \\
& =0 & \text { if } & \mathrm{t} \in(T+1, \ldots, N)
\end{aligned}
$$


In (5) and (6), $D_{t}$ is a dummy variable, taking the value of 1 up to the date of the tested break point $(T)$ and zero afterwards; and $N$ is the last sample observation. The test involves estimating (4) for each point in time belonging to $(1, \ldots N)$. In each estimation, the sample size remains constant but the definition of $D$ changes: for the first estimation, the last observation for $D$ is set to be zero; the rest of the observations are set to be equal to 1 . The estimation is repeated, substituting in each estimation round the values of $D$ by zero backwards. Hence, for the last estimation round, only the first observation of $D$ takes the value of 1; all the rest are set to zero. In each estimation we test the statistical significance of the dummy variables $d_{i}\left(i=1,2\right.$ and 3 ) using a Wald test, which is $\chi^{2}$ distributed with one degree of freedom (see Quintos, 1995) The null hypothesis $\mathrm{H}_{0}: d_{i}=0$ describes structural stability for each of the coefficients in equation (1). ${ }^{13}$ Structural breaks are identified in those dates for which the estimated Wald statistic is higher than the $5 \%$ critical value of $\chi^{2}(1)$. Given that structural breaks cannot fall too close, we follow Quintos (1995) and treat all those falling within two years as representatives of the same structural shift. The exact timing of the break is then selected to be the observation with the highest test value. Assuming $j$ structural breaks for each of the coefficients in (1), the augmented equilibrium price process is then given by (7) below:

$$
p^{*}=\alpha+\beta_{1} u l c_{t}+\beta_{2} p w_{t}+\sum_{i=1}^{j} d_{0 i} D_{i t}+\sum_{i=1}^{k} d_{1 i} D_{i t} u l c_{t}+\sum_{i=1}^{l} d_{2 i} D_{i t} p w_{t}+u_{t}
$$

In (7), $T_{i}$ is the date at which the $i$ th (in a total of $j, k$ and $l$ respectively) identified structural break for each of the three coefficients in (1) ( $\alpha, \beta_{1}$ and $\beta_{2}$ respectively) has been found to occur. $D_{i t}$ is defined to be 0 if $t \in\left(1, \ldots, T_{i}\right)$. If on 
the other hand $t \in\left(T_{i}+1, \ldots, N\right), D_{i t}$ is respectively defined to equal $\alpha, u l c_{t}$ or $p w_{t}$ according to the variable which has been found to be subject to a structural break at period $T_{i}$. Equation (7) picks up the long-run effect of structural breaks on each of the coefficients of the long-run equilibrium price relationship. The cointegrating vector augmented for such breaks is given by $\mathrm{CVBR}_{t}=p^{*}{ }_{t}-\alpha-\beta_{1} u l c_{t}-\beta_{2} p w_{t}$ $-\sum_{i=1}^{j} d_{0_{i}} D_{i t}-\sum_{i=1}^{j} d_{1 i} D_{i t} u l c_{t}-\sum_{i=1}^{j} d_{2 i} D_{i t} p w_{t}$. Finally, if structural breaks exist, In the benchmark price adjustment model in (4) has to be estimated using $\mathrm{CVBR}_{t}$ (which accounts for the breaks) rather than $\mathrm{CV}_{t}$ (which does not) to replace for the error correction term $\left(p-\hat{p}^{*}\right)_{t-1}$

Figure 1 plots the values of the sequentially estimated Chi-square tests for each of the coefficients of equation (1), against the 5 and 1 per cent critical values. We obtain strong evidence of structural instability for each coefficient. For the constant term $\alpha$, stability is rejected for a number of observations in the early $1970 \mathrm{~s}$ and the $1980 \mathrm{~s}$; for $\beta_{1}$ in the early $1980 \mathrm{~s}$; and for $\beta_{2}$ in the mid-1980s and the mid-1990s. Using the criterion of the highest F-statistic for statistically significant values falling close to each other, we find structural breaks of similar timing for the three coefficients, namely 1974Q1 and 1985Q3 for the constant term; 1982Q1 for $\beta_{1}$; and 1974Q1, 1985Q3, 1996Q1 and 1998Q2 for $\beta_{2}$.

We now estimate equation (7) which accounts for the long-run effect of the identified breaks on the price determination relationship. We start from a general specification where all breaks are included in the analysis. The results are reported in Table 1, column (b). This suggests that not all break dummies are significant. Eliminating gradually the insignificant terms, we obtain the parsimonious specification reported in Table 1, col. (c). We conclude that the price determination 
relationship has been subject to three structural breaks, in 1974, 1985 and $1996 .{ }^{14}$ Crucially, for our analysis, we find that the accession of Greece to the EMU in January 2001, and the physical introduction of the Euro in January 2002 have not caused a structural shift in Greek equilibrium consumer prices.

As a robustness check, we superimpose on the data such an EMU-induced break and test for its statistical significance. We do so by adding to the parsimonious equation reported in Table 1, col. (c) dummy variables covering the post-2001 (post-EMU accession) and post-2002 (post Euro-circulation) period respectively, for all three coefficients in equation (3). The results are reported in Table 1, columns (d) and (e). None of the EMU or Euro dummy variables is statistically significant. These remain insignificant when each of the dummies is added to the model on an individual basis. ${ }^{15} \mathrm{We}$ confirm that there exists no econometric evidence to support the hypothesis that Greece's accession to the EMU and/or the introduction of the Euro in physical form have caused any structural increase in equilibrium Greek prices.

Finally, we use the estimated residuals of our preferred long-run equation reported in Table 1, col. (c) as a measure for CVBR to replace for $\left(p-\hat{p}^{*}\right)_{t-1}$ and reestimate the price adjustment model in (3). The results are reported in Table 2, column (b). The estimated speed of adjustment is statistically significant and, compared to the model in column (a), almost four times as fast (14.4 per cent). This highlights the bias dangers involved in empirical papers of price adjustment that do not account for structural breaks in the long-run price determination equation. Allowing for breaks also improves the model's fit, as manifested by the reduction in the standard error of the regression. 


\subsection{Tests and models of non-linear price adjustment}

\subsubsection{Tests of non-linear price adjustment}

We now test formally for the existence of non-linear price adjustment using the procedure described in Saikonnen and Luukkonen (1988), Luukkonen et al (1988), Granger and Teräsvirta (1993) and Teräsvirta (1994). This involves estimating

$\hat{u}_{t}=\gamma_{00}+\sum_{j=1}^{\phi}\left(\gamma_{0 j} \hat{u}_{t-j}+\gamma_{1 j} \hat{u}_{t-j} \hat{u}_{t-d}+\gamma_{2 j} \hat{u}_{t-j} \hat{u}_{t-d}^{2}+\gamma_{3 j} \hat{u}_{t-j} \hat{u}_{t-d}^{3}\right)+\gamma_{4} \hat{u}_{t-d}^{2}+\gamma_{5} \hat{u}_{t-d}^{3}+v_{t}$

where $\hat{u}_{t}$ is the estimated cointegrating vector obtained by (1), or (7), depending on whether (1) has been found to be subject to structural breaks. The parameter $d$ is the delay parameter of the transition function to be used and $v(t) \sim$ niid $\left(0, \sigma^{2}\right)$. Linearity implies the null hypothesis $\mathrm{H}_{0}:\left[\gamma_{1 j}=\gamma_{2 j}=\gamma_{3 j}=\gamma_{4}=\gamma_{5}=0\right]$ for all $j$ $\in(1,2 \ldots \phi)$. This can be tested using an LM-type test. Having determined $\phi=1$ through inspection of the partial autocorrelation function of $\hat{u}_{t},{ }^{16}$ (7) can be estimated for all plausible values of $d$. Non-linearity is rejected if any of the resulting LM-statistics is statistically significant. The optimum value of $d$ is then determined to be the one with the highest LM score.

Table 3 reports the results of the non-linearity tests on CVBR. We obtain evidence of non-linearity, for a number of $d$ values, with the highest F-score observed for $d=7$. We conclude that price adjustment in Greece presents non-linear behaviour, which we proceed to model below. 


\subsubsection{A linear model of size effects in price adjustment}

One way to capture non-linear price adjustment is to use the model proposed by Escribano and Granger (1998) described by equation (9) below:

$$
\Delta p_{t}=\sum_{i=1}^{k} \beta_{i} \Delta p_{t-i}+\sum_{i=0}^{m} \gamma_{i} \Delta \hat{p}^{*}{ }_{t-i}+\delta_{1}\left(p-\hat{p}^{*}\right)_{t-1}+\delta_{2}\left(p-\hat{p}^{*}\right)^{2}{ }_{t-1}+\delta_{3}\left(p-\hat{p}^{*}\right)_{t-1}^{3}+v_{t}
$$

In equation (9), the error correction term enters the price adjustment equation not only in its first power but also in the second and the third. This allows prices to revert to their equilibrium faster for large rather than small deviations from the latter, thus allowing for size effects in the process of price adjustment. We estimate equation (9) using a general-to-specific approach, starting with general specification including twelve lags for $\Delta p_{t}$ and $\Delta \hat{p}^{*}$ and gradually reducing it to a parsimonious one. Table 2, column (c) presents the results. The terms capturing size effects through $\left(p-\hat{p}^{*}\right)^{3}$ is statistically significant with a negative sign, suggesting that the speed of adjustment increases with the size of the deviation from equilibrium. In addition, the model produces an improvement in fit, compared to the models in columns (a) and (b), as manifested by a significant reduction in the regression's standard error.

\subsubsection{A non-linear model of price adjustment}

The Escribano-Granger model discussed above captures non-linear effects in price adjustment within a linear econometric estimation framework. From that point of view, it can only approximate, rather than model precisely, the nonlinearities involved in the process of price adjustment. To do so, we estimate the Quadratic Logistic Smooth Threshold Error Correction Model (QL-STECM). This 
model, which is a generalisation of the ESTAR model, is described by equations (10) to (13) below (see van Dijk et al., 2002):

$$
\begin{aligned}
& \Delta p_{t}=\theta_{t} R_{\mathrm{I} t}+\left(1-\theta_{t}\right) R_{\mathrm{O} t}+\varepsilon_{\mathrm{t}} \\
& R_{\mathrm{I} t}=\alpha_{1}+\sum_{i=1}^{n} \beta_{I i} \Delta p_{t-i}+\sum_{i=0}^{p} \gamma_{I i} \Delta \hat{p}^{*}{ }_{t-i}+\delta_{\mathrm{I}}\left(p-\hat{p}^{*}\right)_{t-1}+\varepsilon_{\mathrm{It}} \\
& R_{\mathrm{O} t}=\alpha_{2}+\sum_{i=1}^{n} \beta_{O i} \Delta p_{t-i}+\sum_{i=0}^{p} \gamma_{O i} \Delta \hat{p}^{*}{ }_{t-i}+\delta_{\mathrm{O}}\left(p-\hat{p}^{*}\right)_{t-1}+\varepsilon_{\mathrm{Ot}} \\
& \theta_{t}=p r\left\{\tau^{L} \leq\left(p-\hat{p}^{*}\right)_{t-d} \leq \tau^{U}\right\}=1-\frac{1}{1+e^{-\sigma\left[\left(p-\hat{p}^{*}\right)_{t-d}-\tau^{L}\right]\left[\left(p-\hat{p}^{*}\right)_{t-d}-\tau^{U}\right]}}
\end{aligned}
$$

The QL-STECM involves two regimes, the inner $\left(\mathrm{R}_{\mathrm{I}}\right)$ and the outer $\left(\mathrm{R}_{\mathrm{O}}\right)$, described by equations (11) and (12) respectively. These are linear price adjustment equations similar to (2) and respectively describe price adjustment for small and large deviations from equilibrium. The inner regime is defined by two threshold values, the upper $\left(\tau^{\mathrm{U}}\right)$ and the lower $\left(\tau^{\mathrm{L}}\right)$. The thresholds define a band within which the speed of price adjustment takes a value different to the one prevailing outside the band. Equation (13) models the probability that the transition variable $\left(p-\hat{p}^{*}\right)_{t-d}$ takes values within the inner regime using the quadratic logistic function. Menu costs and other market imperfections imply that reversion of prices to their equilibrium is faster when deviation from the latter is large rather than small, i.e. $\left|\delta_{\mathrm{O}}\right|>\left|\delta_{\mathrm{I}}\right|$. The QL-STECM also captures a certain type of sign effects in price adjustment if the regime thresholds are asymmetric $\left(\tau^{\mathrm{L}}+\tau^{\mathrm{U}} \neq 0\right)$. This asymmetry, if validated by the data, allows one form of disequilibrium (positive or negative) to be sustained longer than the other before the outer regime is reached. 
The results from estimating the QL-STECM model using the cointegrating vector accounting for structural breaks (CVBR) are reported in Table 2, column (d). The error correction coefficient is significant in both regimes. In the inner regime, the quarterly speed of adjustment to equilibrium is estimated to be 13.2 per cent. In the outer regime, however, adjustment is more than three times as fast quite fast (45.3 per cent).

Finally, the threshold symmetry restriction reported at the end of the Table is not significant, so the inner regime's thresholds are found to be symmetric $\left(\tau^{\mathrm{L}}=\tau^{\mathrm{U}}\right)$. With the point estimates for $\tau^{\mathrm{L}}$ and $\tau^{\mathrm{U}}$ being equal to -2.28 and 1.93 respectively, the model suggests that the inner regime is defined to be within two percentage points from the equilibrium price level. We have tested the robustness of these findings by estimating a number of models allowing for sign effects in the behaviour of Greek prices, i.e. models which allow different speed of adjustment for positive and negative deviations from equilibrium. More specifically, we estimated the Granger-Lee (1989) model, a composite model combining the Granger and Lee specification with that by Escribano and Granger in (9), the Logistic STECM model, and the 3-stage STECM model discussed van Dijk et al. (2002). In all cases, we evidence of size but no sign effects in the process of shortrun price adjustment. In addition, all these models produced a higher regression standard error when compared to the Escribano-Granger and QL-STECM models reported in Table $2 .^{17}$ 


\section{DISCUSSION OF EMPIRICAL RESULTS: EXPLAINING THE POST- EMU ACCESSION INCREASE IN GREEK CONSUMER PRICES}

Our analysis in the previous section rejected the widely-held hypothesis according to which joining the single currency is the factor underlying the increase in Greek consumer prices observed following the accession of Greece to the EMU. So why did these take place? Figure 2, which plots the estimated disequilibrium term accounting for structural breaks (CVBR) versus the estimated regime thresholds of the QL-STECM model, provides some explanations.

First, Figure 2 shows that during the run-up to EMU accession in 19982000, the Greek price level took values increasingly below its equilibrium level. This is a period during which Greek authorities introduced a number of pricerestraining measures, including freezing or increasing only marginally the prices of public utilities and concluding agreements with unions of Greek private firms, involving restraints on the latter's pricing policy. These aimed to ensure meeting the inflation criterion set by the Maastricht Treaty so that Greece would be able to join the EMU in 2001. This target was eventually met but, as Figure 2 suggests, these measures meant that for a period of two years prior to EMU accession, consumer prices were falling more and more behind their equilibrium level. Following Greece's accession to the EMU in 2001, which eliminated the basis on which the measures were taken, for prices to catch-up with their equilibrium level their rate of growth was bound to accelerate. Note that this conclusion stands even if the speed of price adjustment were to be a linear process.

The second factor explaining post-EMU accession price behaviour in Greece relates to our finding that price adjustment in that country is, in fact, a nonlinear process. Figure 2 suggests that at the eve of Greece's accession to the EMU 
(late 2000), the Greek price level was not only lower than its equilibrium level, but it was also low enough to have hit, and marginally surpassed, the lower threshold of the inner regime $\left(\tau^{\mathrm{L}}\right)$. Under such conditions, the QL-STECM model predicts that prices would not only increase; but they would also increase fast to correct the existing large disequilibrium. Indeed, as Figure 2 shows, this is what has happened on all previous occasions when prices took values in the outer regime below their equilibrium (1973, 1977-78, 1985-86 and 1989-90) and, in line with these episodes, immediately after the under-pricing episode of 2000.

To summarise, our findings suggest that at the early stages of EMU participation (2001-2002) Greek consumer prices did not accelerate because of the introduction of the Euro; they accelerated because of the existence of strong underpricing pressures prior to the adoption of the Euro. From that point of view, there is nothing surprising in their behaviour. Their movements represent normal equilibrium-restoring price behaviour.

Figure 2 suggests that following their restoration to equilibrium level in mid-2002, consumer prices continued to increase so that by the end of 2003, they were above their equilibrium level (in one occasion, in the outer regime). One explanation for this overshooting is that this is an over-reaction to the under-pricing episode discussed above, similar to the one that took place following all previous under-pricing episodes depicted in Figure 2. In addition, there exist another two, non-mutually exclusive, possible explanations.

The first is a supply-based hypothesis, according to which Greek firms have deliberately been increasing prices beyond equilibrium in pursuit of higher profits. This hypothesis is not testable without using micro data, but it is not unreasonable, 
especially in view of the profitability losses Greek firms may have suffered during the prolonged under-pricing episode of the late 1990s.

The second is a demand-based hypothesis according to which the increase in Greek prices beyond their equilibrium level in 2003 reflects an incompatibility between the domestic requirements of the Greek economy and the monetary policy followed by the European Central Bank. According to this hypothesis, during 2001-2003, a period when the Greek rate of output growth was four times higher than the EMU average, Greece needed relatively high interest rates to prevent highdemand conditions resulting in significant price increases. Instead, Greece experienced, along with the rest of the EMU members, interest rate reductions, aiming to revive economic activity in the face of subdued economic growth in the EMU area (see ECB, 2004 pp. 91-92). ${ }^{18}$ We have tested this incompatibility hypothesis in another paper, belonging to the same research project the present paper belongs, and have found significant econometric evidence in support of it.

\section{SUMMARY AND CONCLUDING REMARKS}

This paper tested the widely-held hypothesis according to which accession to the EMU has caused a structural increase in Greek consumer prices. We find that joining the single currency did not cause such an effect. We also find strong evidence of (a) multiple structural breaks in the process driving equilibrium prices and (b) non-linear price adjustment. Our findings explain the post-EMU accession acceleration in Greek prices as normal, equilibrium-restoring price behaviour.

Our findings also have important policy implications for the new EU members planning to join the EMU in the foreseeable future. These present a number of similarities with Greece before the latter's accession to the Euro. 
Despite the well-established productivity gains these countries have achieved in the 1990s, their productivity remains below that of the EMU average; they have large non-traded sectors; and their aggregate price level, when expressed in Euros, is below the Euro-zone average (see, Taylor and Sarno (2001), Dibooglu and Kutan (2001) and the references therein).

The Greek experience shows that these countries will not necessarily pay an "admission cost" upon entering in the EMU in the form of an upward structural shift in their consumer price level. However, joining the single currency may in practice be accompanied by significant price increases, if pre-accession inflation convergence is not entirely market-achieved but also administratively enhanced. The Greek experience also suggests that if the new EU members do not achieve adequate synchronization of their business cycle with that of the EMU average, EMU entry may lead to incompatibility between the single monetary policy and their domestic economic conditions. To avert this eventuality, prior to entering the single currency they should aim to achieve a higher degree of real convergence than the one achieved by Greece in the 1990s.

\section{ACKNOWLEDMENTS}

This paper presents some of the findings of the research project titled The effects of joining the Euro on the Greek Economy: Initial estimates and future prospects, commissioned and funded by the Centre of Planning and Economic Research (KEPE) of the Ministry of Finance of the Hellenic Republic. I wish to thank KEPE and the Hellenic Ministry of Finance for commissioning and supporting financially this project. I would also like to thank the officials of KEPE and the Hellenic Ministry of Finance for the presentation of the project's findings at KEPE, in November 2004, and providing me with useful comments and suggestions. Thanks are also due to Christopher Martin for comments on a previous draft of this paper. The usual disclaimer applies. 


\section{REFERENCES}

Alogoskoufis G. (1995), "The two faces of Janus: Institutions, Policy Regimes and Macroeconomic Performance in Greece”, Economic Policy 20, pp. 149-192.

Andrews D. W. K. (1993), "Tests for Parameter Instability and Structural Change With Unknown Change Point", Econometrica, 61, pp. 821-856.

Asea P.K. and Coden W.M. (1994), "The Balassa-Samuelson Model: An Overview", Review of International Economics 2, pp. 191-200.

Arghyrou M.G., Martin C. and Milas C. (2004), "Non-linear Inflationary Dynamics: Evidence from the UK", Oxford Economic Papers, forthcoming.

Balassa B. (1964), "The purchasing power parity doctrine: a reappraisal”, Journal of Political Economy 72, pp. 584-596.

Deveraux M.B. and Siu H.E. (2004), "State dependent pricing and business cycles asymmetries", Department of Economics, The University of British Columbia, Discussion Paper 04-13.

Dibooglu S. and Kutan A.M. (2001), "Sources of Real Exchange rate Fluctuations in Transition Economies: The case of Poland and Hungary", Journal of Comparative Economics 29, pp. 257-275.

Engle, R.F. and C.W.J. Granger (1987), "Cointegration and error-correction: representation, estimation and testing", Econometrica, 55, 251-276.

Escribano, A. and C.W.J. Granger (1998), "Investigating the relationship between gold and silver prices", Journal of Forecasting, 17, 81-107.

European Central Bank (2004), The Monetary Policy of the ECB, Frankfurt am Main.

Froot K.A. and Rogoff K. (1995), "Perspectives on PPP and long-run real exchange rates", in G.M. Grossman and K. Rogoff (eds.), Handbook of International Economics, vol. III, Amsterdam: North-Holland, pp. 1647-1688.

Granger, C.W.J. and T.H. Lee (1989), "Investigation of production, sales and inventory relationships using multicointegration and non-symmetric error correction models", Journal of Applied Econometrics, 4, S145-S159.

Granger, C.W.J. and T. Teräsvirta (1993), Modelling Non-linear Economic Relationships, Oxford University Press, Oxford.

Gregory A.W. and Hansen B. E. (1996), "Residual-based test for cointegration in models with regime shifts", Journal of Econometrics, 70, pp. 99-126.

Hendry, D.F. (2001), "Modelling UK Inflation, 1875-1991”, Journal of Applied Econometrics, 16, 255-275. 
Kenen, P. (1969), "The Theory of Optimum Currency Areas: an Eclectic View", in R. Mundell and A. Swobodaa (eds.), Monetary Problems of the International Economy, University of Chicago Press, Chicago.

Luukkonen R., Saikkonnen P. and Teräsvirta (1988), “Testing linearity against smooth transition autoregressive models", Biometrika 75, pp. 491-499.

Maddala G.S. and Kim I.M. (1998), Unit Roots, Cointegratoin and Structural Change, Cambridge University Press: Cambridge.

Martin C. and Milas C. (2004), "Modelling monetary policy: inflation targeting in practice", Economica, (forthcoming).

McKinnon R. (1963), “Optimum Currency Areas”, American Economic Review 53, pp. 717-725.

Mourmouras, I.A. and Arghyrou, M.G. (2000), Monetary Policy at the European Periphery: Greek Experience and Lessons for EU Candidates, book in the European and Transatlantic Studies Series, Springer-Verlag, Berlin - New York.

Mundell R. (1961), “A Theory of Optimal Currency Areas", American Economic Review 51, pp. 657-665.

Quintos C. E. (1995), "Sustainability of the Deficit Process with Structural Shifts", Journal of Business \& Economic Statistics 13, pp. 409-417.

Rogoff K. (1996), "The Purchasing Power Parity Puzzle", Journal of Economic Literature 34, pp. 647-668.

Sarno L. and Taylor M. (2002), The economics of exchange rates, Cambridge: Cambridge University Press.

Saikonnen P. and Luukkonen R. (1988), "Lagrange multiplier tests for testing nonlinearities in time series models", Scandinavian Journal of Statistics 15, pp. 55-68.

Samuelson P.A. (1964), "Theoretical notes on trade problems", Review of Economics and Statistics 46, pp. 145-154.

Stock J. and Watson M. (1993), "A Simple Estimator of Cointegrating Vectors in Higher Order Integrated Systems”, Econometrica 55, pp. 1035-1056.

Taylor M.P. and Sarno L. (2001), "Real exchange rate dynamics in transition economies: a non-linear analysis", Studies in Non-Linear Dynamics \& Econometrics vol. 5, issue 3, Article 1.

Taylor M.P. and Sarno L. (2002), The Economics of the Exchange Rates, Cambridge University Press. 
Teräsvirta T. (1994), "Specification, estimation and evaluation of smooth transition autoregressive models", Journal of the American Statistical Association 89, pp. 208-218.

van Dijk, D., T. Teräsvirta, and P.H. Franses (2002), "Smooth transition autoregressive models - a survey of recent developments", Econometric Reviews, 21, 1-47.

\section{ENDNOTES}

${ }^{1}$ For a thorough survey of empirical studies on price distortions caused by exchange rate variability, marking-to-market pricing policies and other trade barriers, see Sarno and Taylor (2002).

${ }^{2}$ For a justification of this argument, see the detailed analysis on the determinants of the Greek aggregate price level in 1990s in Mourmouras and Arghyrou (2000), chapter 5.

${ }^{3}$ See, for example, Rogoff (1996).

${ }^{4}$ For a theoretical justification of the Balassa-Samuelson hypothesis see, among others, Froot and Rogoff, (1995). For a survey of related theoretical models and empirical evidence see Asea and Corden (1994).

${ }^{5}$ For a theoretical justification of these econometric specifications, and other references in which they have been adopted, see Arghyrou, Martin and Milas (2004).

${ }^{6}$ An alternative methodology consists of substituting (2) into (1) and estimate $\Delta p_{t}=\Sigma \beta_{i} \Delta p_{t-i}+$ $\Sigma \gamma_{i} \Delta p_{t-i}+\delta\left(p-\beta^{\prime} z\right)_{t-1}+v_{t}$. However, working with equation (3) is preferable when estimating models with a large number of parameters like the non-linear model we estimate below.

${ }^{7}$ For the post-EMU accession period (2001 onwards), we calculated the drachma value of world prices first by calculating their euro value (by multiplying the world consumer prices index expressed in dollars by the Euro/US dollar exchange rate; and then multiplying the resulting product by the irrevocable Drachma/Euro exchange rate (340.75)

${ }^{8}$ This index is taken from the OECD Historical Data Databank provided by DataStream.

${ }^{9}$ Preliminary unit root analysis (not reported here but available upon request) suggests that $u l c$ is integrated of order one. The order of integration of $p$ and $p w$ is more ambiguous. Ambiguity for the order of integration of price-level series is a theme frequently encountered in empirical literature, with the prevailing view being that inflation is a stationary. Following this, we treat $p$ and $p w$ as I(1) variables (for further discussion on this point, see Martin and Milas 2004 and the references therein).

${ }^{10}$ As a robustness check, we have estimated equation (1) using the Generalised Dynamic OLS method (see Stock and Watson, 1993). This method adds to the right hand side of equation (1) a number of lead and lag terms relating to the independent variables aiming to account for any possible feedback effects between the left- and right- hand side terms. The results we obtained are very similar to those reported in Table 1, col. (a) with the long-run equation being estimated as $p_{t}=$ $-0.445+0.540 u l c_{t}+0.306 p w_{t}+u_{t}$.

${ }^{11}$ The lag structure of the ADF statistics reported in Table 1 is determined using the Akaike information criterion.

${ }^{12}$ This equation, and all equations in Table 2, are estimated with two intercept dummies taking the value of unity for 1979Q1 and 1985Q4 respectively, and zero otherwise. Their inclusion does not change the nature of results but ensures that the equations pass the reported misspecification tests.

${ }_{13}$ Andrew (1993) proposes trimming the initial and final parts of the sample when testing for structural stability. We have tested for structural breaks trimming our sample as suggested by Andrews and found results very similar to those reported below (these are available upon request). However, we prefer to use the results without trimming because the date of the accession of Greece to the EMU (January 2001) falls into the final part of the sample which is trimmed.

${ }^{14}$ The timing of the identified breaks can be related to macroeconomic events of significance for the Greek economy. The break in 1974 can be related to the first oil shock. The break of 1985 may be related to the fiscal and monetary expansion that took place in Greece in the first half of the 1980s. Finally, the break of 1996 can be related to stabilisation effort undertook in the context of the Greek convergence programmes implemented in the 1990s. For a thorough discussion of Greek macroeconomic policy and performance during the period 1974-1995, see Alogoskoufis, 1995. 


\footnotetext{
${ }^{15}$ The EMU and Euro dummies remain insignificant when they are added to the parsimonious equation accounting for the structural breaks derived when, in line with Andrews (1993) we trim the initial and final parts of the sample. The results are available upon request.

${ }^{16}$ Granger and Teräsvirta (1993) and Teräsvirta (1994) advise against choosing $\phi$ using an information criterion such as the Akaike, since this may induce a downward bias.

${ }^{17}$ To preserve space, these results are not reported here but are available upon request.

18 This hypothesis is consistent with one of the main predictions of the Theory of Optimum Currency Areas formulated as early as the 1960s (see Mundell (1961), McKinnon (1963) and Kenen (1969)), according to which joining a monetary union without having achieved significant synchronisation with the business cycle of the rest of the union members may result in pro-cyclical and destabilising monetary policy.
} 


\section{Table 1}

\section{Long-run models}

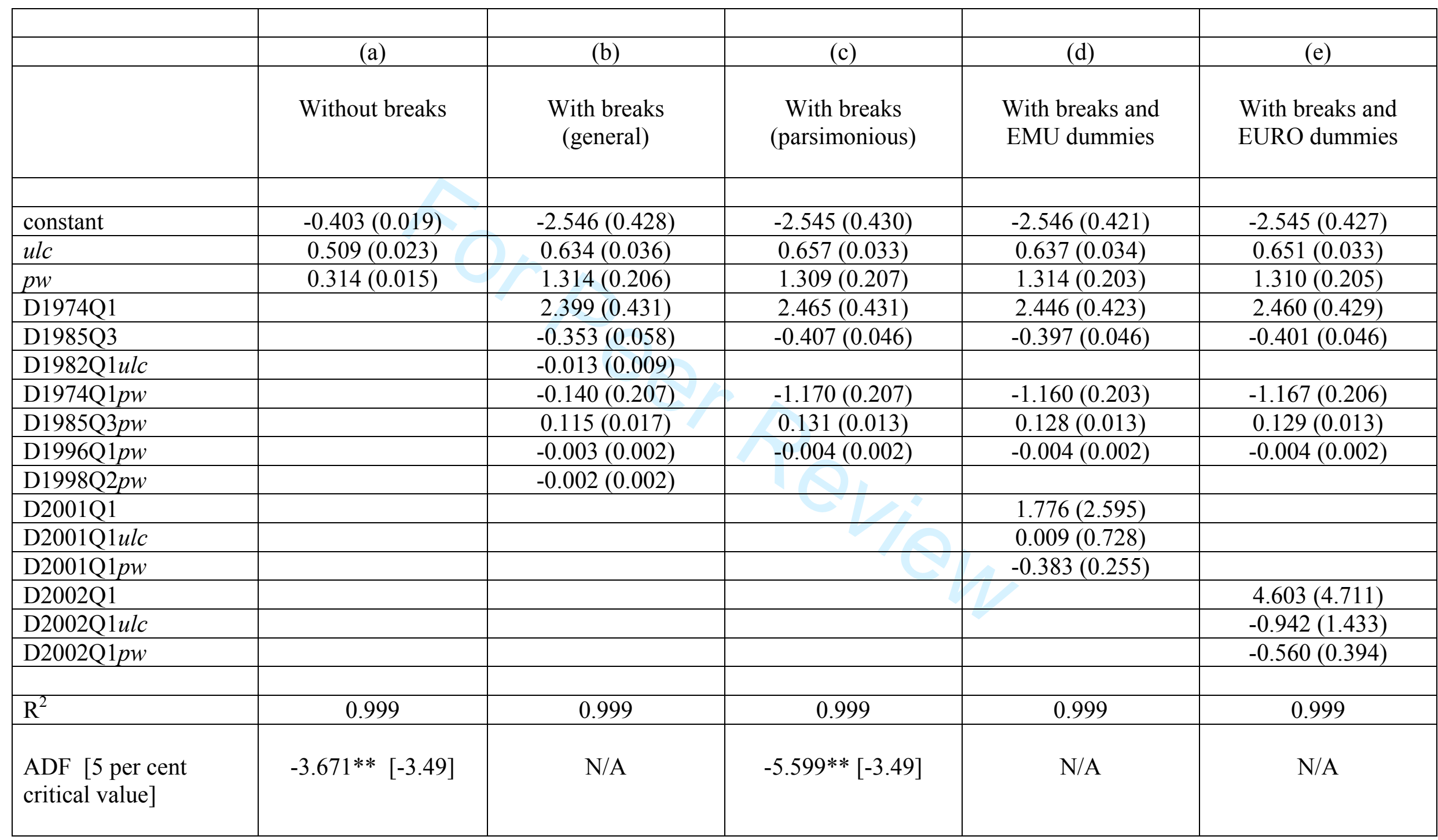

Notes: Standard errors in parentheses; $* *$ denotes statistical significance at the 1 per cent level 
Table 2

Short-run price-adjustment models

\begin{tabular}{|c|c|c|c|c|}
\hline & (a) & (b) & (c) & (g) \\
\hline & $\begin{array}{c}\text { Linear } \\
\text { without breaks }\end{array}$ & $\begin{array}{c}\text { Linear } \\
\text { with breaks }\end{array}$ & $\begin{array}{c}\text { Linear } \\
\text { with breaks and size effects }\end{array}$ & $\begin{array}{l}\text { Non-linear } \\
\text { QLSTAR }\end{array}$ \\
\hline & & & & $\mathrm{R}_{\mathrm{I}}-$ Inner Regime \\
\hline Constant & $0.0008(0.0009)$ & $-0.0006(0.0008)$ & $0.0001(0.0009)$ & $-0.0004(0.0007)$ \\
\hline $\mathrm{D} p_{\mathrm{t}-1}$ & $0.194(0.061)$ & $0.147(0.051)$ & $0.167(0.053)$ & \\
\hline $\mathrm{D} p_{\mathrm{t}-2}$ & & $0.104(0.048)$ & $0.118(0.050)$ & $0.155(0.045)$ \\
\hline $\mathrm{D} p_{\mathrm{t}-3}$ & & $0.130(0.060)$ & $0.131(0.060)$ & \\
\hline $\mathrm{D} p_{\mathrm{t}-4}$ & $0.391(0.057)$ & $0.414(0.051)$ & $0.406(0.051)$ & $0.519(0.055)$ \\
\hline $\mathrm{D} p_{\mathrm{t}-7}$ & $-0.100(0.050)$ & & & \\
\hline $\mathrm{D} p_{\mathrm{t}-8}$ & $0.304(0.057)$ & $0.269(0.050)$ & $0.367(0.054)$ & $0.202(0.051)$ \\
\hline $\mathrm{D} p_{\mathrm{t}-9}$ & $-0.130(0.060)$ & & & \\
\hline $\mathrm{D} p_{\mathrm{t}-11}$ & 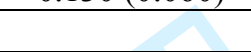 & $-0.120(0.052)$ & $-0.092(0.049)$ & \\
\hline $\mathrm{D} p^{*}$ & $0.114(0.039)$ & $0.141(0.032)$ & $0.161(0.032)$ & $0.130(0.026)$ \\
\hline $\mathrm{D} p^{*}{ }_{t-1}$ & $0.085(0.032)$ & & & \\
\hline $\mathrm{D} p_{\mathrm{t}-4}^{*-1}$ & $-0.078(0.035)$ & $-0.110(0.029)$ & $-0.113(0.030)$ & \\
\hline $\mathrm{D} p_{\mathrm{t}-7}$ & $0.080(0.033)$ & & & \\
\hline $\mathrm{D} p^{*-8}$ & & & $-0.058(0.029)$ & \\
\hline $\mathrm{D} p_{\mathrm{t}-9}$ & & 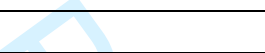 & $-0.055(0.028)$ & \\
\hline $\mathrm{D} p^{*}{ }_{\mathrm{t}-10}$ & & $-0.061(0.027)$ & $-0.080(0.028)$ & $-0.072(0.023)$ \\
\hline $\mathrm{D} p^{*} t-11$ & & $0.061(0.027)$ & & \\
\hline $\mathrm{CV}_{\mathrm{t}-1}$ & $-0.044(0.019)$ & (n) & & \\
\hline $\mathrm{CVBR}_{\mathrm{t}-1}$ & & $-0.144(0.026)$ & $-0.103(0.035)$ & $-0.132(0.027)$ \\
\hline$\left(\mathrm{CVBR}_{\mathrm{t}-1}\right)^{3}$ & & 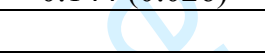 & $-70.458(32.650)$ & \\
\hline & & 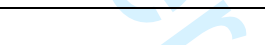 & & $\mathrm{R}_{\mathrm{O}}-$ Outer Regime \\
\hline Constant & & & 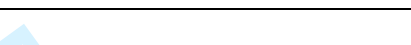 & $-0.0002(0.0029)$ \\
\hline $\mathrm{D} p_{\mathrm{t}-3}$ & & & 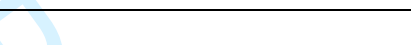 & $0.866(0.231)$ \\
\hline $\mathrm{D} p_{\mathrm{t}-7}$ & & & res & $-0.588(0.247)$ \\
\hline $\mathrm{D} p_{\mathrm{t}-11}$ & & & 2 & $0.547(0.286)$ \\
\hline $\mathrm{D} p^{*}-8$ & & & +2 & $0.537(0.121)$ \\
\hline $\mathrm{D} p^{*}{ }_{\mathrm{t}-12}$ & & & $\bar{c}$ & $-0.259(0.077)$ \\
\hline $\mathrm{CVBR}_{\mathrm{t}-1}$ & & & 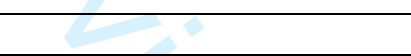 & $-0.453(0.059)$ \\
\hline & & & $8=$ & \\
\hline$\tau^{\mathrm{U}}$ & & & 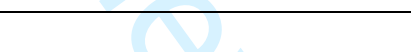 & $0.0193(0.0003)$ \\
\hline$\tau^{\mathrm{L}}$ & & & $=0$ & $-0.0228(0.0036)$ \\
\hline & & & 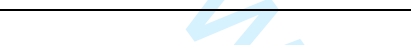 & \\
\hline Regression SE & 0.00413 & 0.00367 & 0.00360 & 0.00340 \\
\hline $\mathrm{R}^{2}$ & 0.861 & 0.891 & 0.897 & 0.911 \\
\hline & & & & \\
\hline$\overline{A R-F}$ & $1.18[0.32]$ & $1.40[0.23]$ & $2.27[0.06]$ & $0.67[0.65]$ \\
\hline ARCH-F & $7.41[0.00]$ & $5.29[0.00]$ & $2.50[0.05]$ & $1.13[0.35]$ \\
\hline Normality Chi-sq & $4.72[0.09]$ & $2.62[0.27]$ & $0.13[0.94]$ & $1.90[0.39]$ \\
\hline Hetero-F & $1.10[0.37]$ & $1.19[0.28]$ & $0.76[0.79]$ & $0.97[0.54]$ \\
\hline RESET & $1.45[0.23]$ & $0.01[0.95]$ & $0.06[0.80]$ & N/A \\
\hline $\begin{array}{l}\text { Threshold symmetry } \\
\text { F-test [5\% cr. value] }\end{array}$ & & & & $2.28[3.90]$ \\
\hline
\end{tabular}

NOTES: Numbers in parentheses denote standard errors; p-values in square brackets, unless other wise stated; AR-F is the Lagrange Multiplier F-test for residual serial correlation; ARCH-F is a general misspecification test of Autoregressive Conditional Heteroscedasticity; Normality Chi-sq is the Bera-Jarque test for residual non-normality Hetero- F is an F-test for heteroskedasticity. 


\section{Table 3}

Tests for non-linear adjustment of the cointegrating vector accounting for breaks

\begin{tabular}{|c|c|c|}
\hline & & p-value \\
\hline$d$ & F-test & \\
\hline 2 & & $0.028^{*}$ \\
\hline 4 & 2.603 & $0.001^{* *}$ \\
\hline 5 & 4.399 & $0.016^{*}$ \\
\hline 7 & 2.926 & $0.001^{* *}$ \\
\hline & 4.733 & \\
\hline
\end{tabular}

Note: The Table reports the F-scores of the LM test described in equation (8); * and ** denote statistical significance at the 5 and 1 per cent level respectively 
Submitted Manuscript

Page 26 of 27

Figure 1: Chi-square tests for structural stability

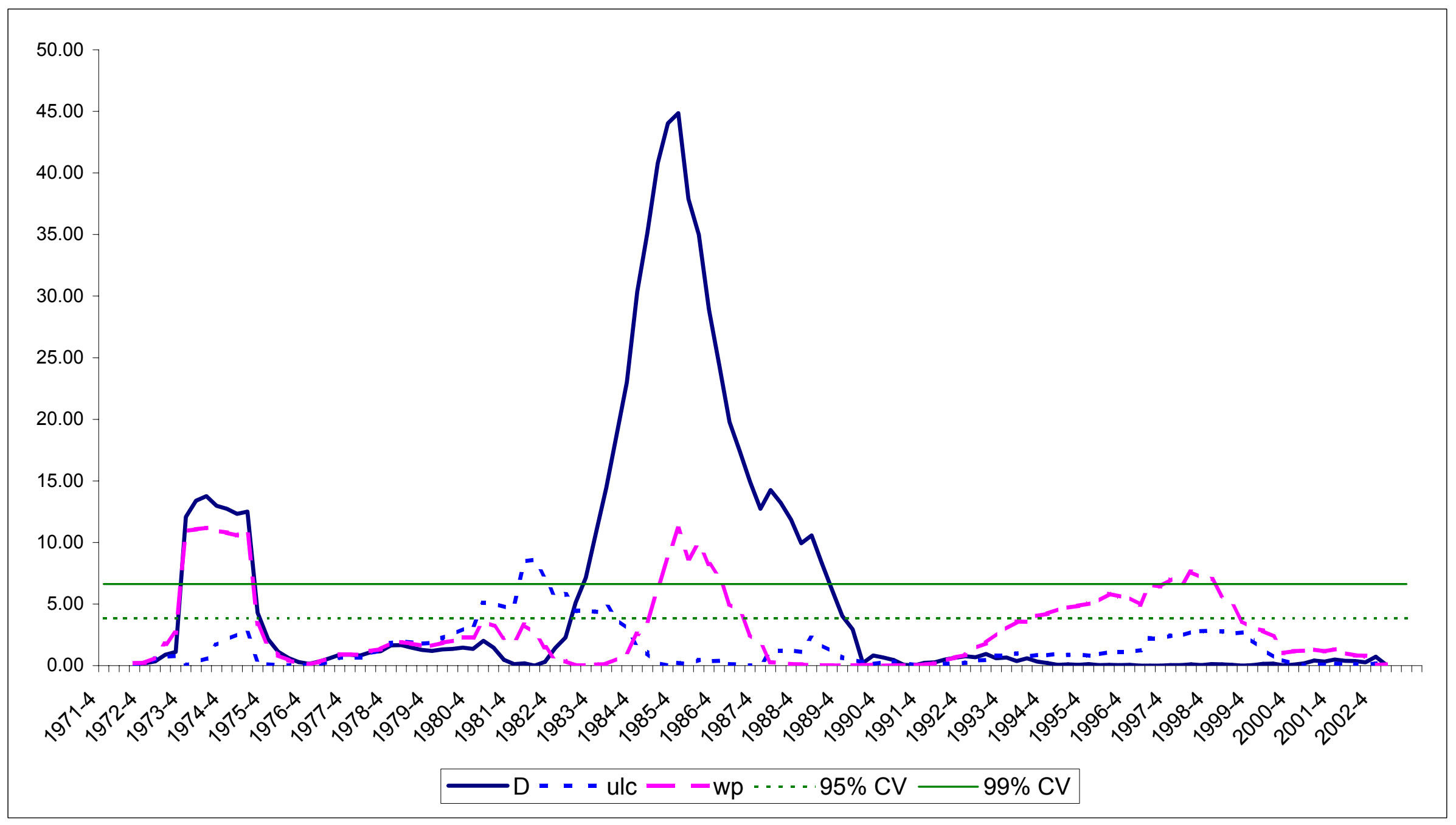

24

Editorial Office, Dept of Economics, Warwick University, Coventry CV4 7AL, UK 
Figure 2: Cointegrating vector accounting for structural breaks v estimated thresholds of inner price-adjustment regime

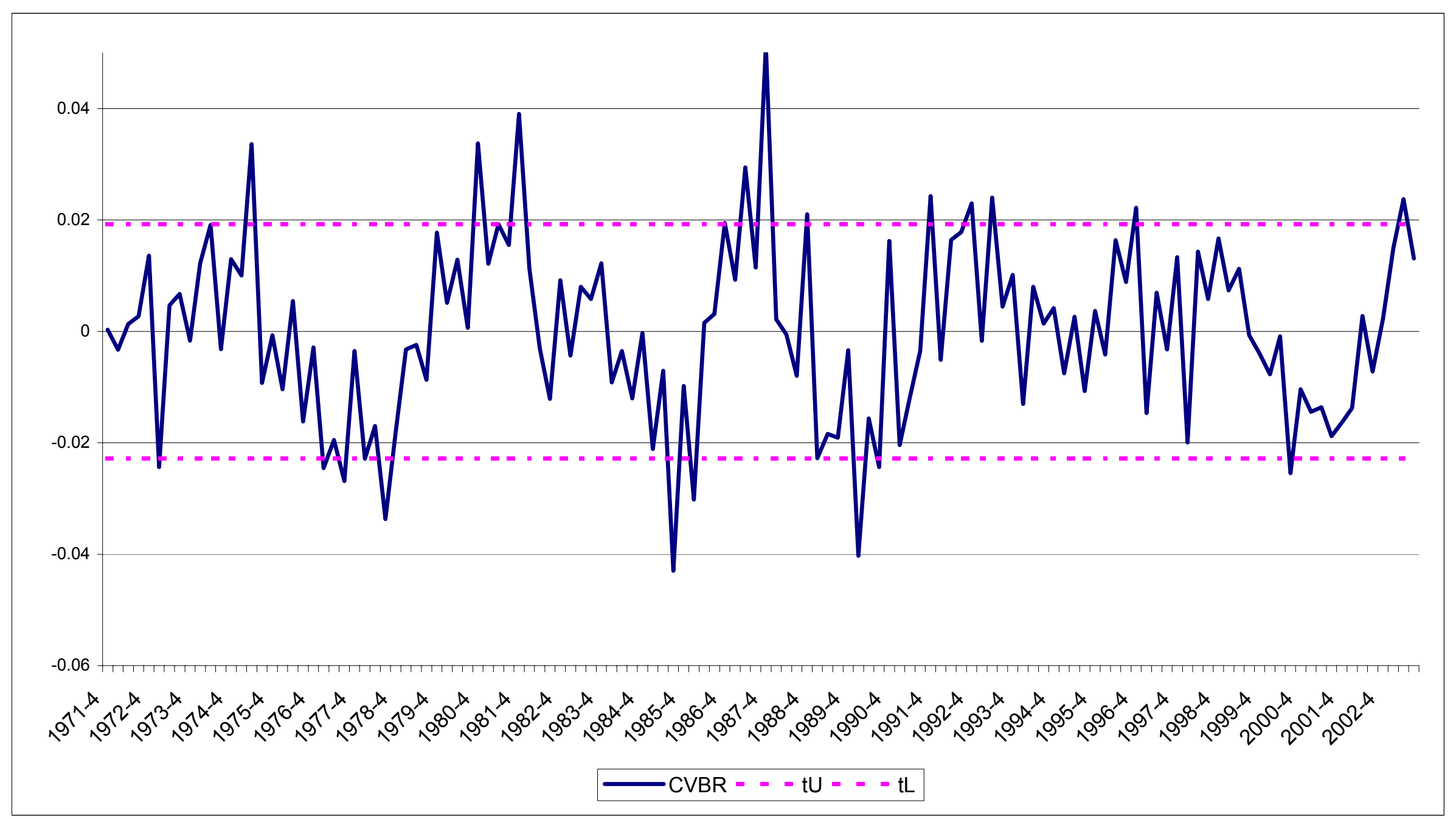

